\title{
AS CONTRIBUIÇÕES DO MOVIMENTO QUILOMBOLA PARA A CONSTRUÇÃO DE UMA PROPOSTA DE EDUCAÇÃO ESPECÍFICA
}

\author{
Agda Marina Ferreira Moreira (UEMG)* \\ José Eustáquio de Brito (UEMG)**
}

\section{RESUMO}

Os processos educativos e de formação político-identitários reproduzidos no interior de cada comunidade remanescente de quilombo, juntamente com as experiências advindas dos movimentos sociais quilombolas, são aspectos indispensáveis na discussão de implementação de uma modalidade escolar quilombola. Partindo de um estudo de caso, apresentaremos resultados das observações oriundas da comunidade quilombola de Carrapatos da Tabatinga e do movimento quilombola mineiro, bem como da pesquisa de dissertação de mestrado em Educação e da trajetória profissional na ONG Cedefes e na N'Golo. Para tanto, utilizamos por método a observação participantes, além de trechos de entrevistas centradas no problema, realizadas no campo de pesquisa. Dentre os resultados apresentados, buscaremos enfatizar as formas de se educar construídas nas trocas cotidianas e nas interações com as mobilizações políticas, sendo ambas importantes produtoras de pedagogias próprias, que se relacionam diretamente às reinvindicações e aos aspectos tradicionais presentes nas comunidades quilombolas, sendo parte de uma cosmovisão africana. Em constante diálogo, comunidades e movimento nos instigam a reconhecer formas alternativas de formação de sujeitos engajados, que se reconhecem enquanto quilombolas e que são responsáveis diretos pela preservação dos saberes-fazeres construídos nos espaços de suas respectivas comunidades.

Palavras-chave: Processos educativos. Movimento quilombola. Formação identitária. Educação quilombola.

\section{ABSTRACT \\ THE CONTRIBUTIONS OF THE QUILOMBO MOVEMENT TO THE CONSTRUCTION OF A SPECIFIC PROPOSAL FOR EDUCATION}

Educational processes and processes of political identity formation developed within each runaway descendant community, along with the experiences derived from runway community social movements are indispensable elements in discussing the implementation of a runaway community school model. Based on a case study, we present the results of observations made with the runaway community of Carrapatos da Tabatinga (State of Minas Gerais, Brazil) and the entire Minas Gerais runaway

\footnotetext{
* Mestre em Educação pela Universidade do Estado de Minas Gerais UEMG). Assessora executiva da Federação das Comunidades Quilombolas do Estado de Minas Gerais. E-mail: agda.quilombos@gmail.com

** Doutor em Educação pela Universidade Federal de Minas Gerais (UEMG). Vice-reitor e docente da UEMG. E-mail: joseeustaquio.brito@uemg.br
} 
movement, in a Masters' Dissertation study carried out while working with NGOs Cedefes and N'Golo. These were made while developing participant observation, and with fragments of problem-based interviews carried out during the research. Among the results presented, we seek to emphasize forms of education which focus on everyday exchanges and interactions resulting from political mobilizations, which are both presented as producing their own pedagogical methods, in turn directly related to the specific demands and traditional aspects present at runaway communities, as integral parts of African worldviews. In a constant dialogue, communities and political movement encourage a recognition of alternative ways of forming engaged subjects, who recognize themselves as members of runaway communities and as directly responsible for the preservation of know-how constructed in their respective communities.

Keywords: Educational processes. Quilombola movement. Identity formation. Quilombola education.

\section{RESUMEN}

\section{LAS CONTRIBUCIONES DEL MOVIMIENTO QUILOMBOLA PARA LA CONSTRUCCIÓN DE UMA PROPUESTA DE EDUCACIÓN ESPECÍFICA}

Los procesos educativos y de formación político-identitaria que se reproducen en el seno de cada comunidad descendiente de quilombos, junto con las experiencias fruto de sus correspondientes movimientos sociales son aspectos indispensables para discutir la implementación de una modalidad escolar propia. Partiendo de un estudio de caso, presentaremos los resultados de observaciones realizadas en el seno de la comunidad de Quilombo de Carrapatos da Tabatinga y del movimiento de los quilombos de Minas Gerais, así como la investigación de disertación de Maestría en Educación y de la trayectoria profesional de la ONG Cedefes e na N'Golo. Para ello utilizamos el método de la observación participante, junto con tramos de entrevistas centradas en el problema realizadas En el campo de la investigación. Entre los resultados presentados buscaremos enfatizar formas de educarse construidas en los intercambios cotidianos y en las interacciones con las movilizaciones políticas, dos importantes fuentes de pedagogías propias que se relacionan directamente con las reivindicaciones y con los aspectos tradicionales presentes en las comunidades de quilombos, y que forman parte de una cosmovisión africana. En constante diálogo, comunidades y movimiento instigan a reconocer formas alternativas de formación de sujetos comprometidos, que se reconocen como miembros de estos quilombos -quilombolas- y que son responsables directos de la preservación de saberes- haceres construidos en los espacios de sus respectivas comunidades.

Palabras clave: Procesos educativos. Movimiento de los quilombos. Formación identitaria. Educación en los quilombos. 


\section{Introdução}

$\mathrm{O}$ advento dos remanescentes de quilombos enquanto categoria social reconhecida pelo Estado brasileiro demarca uma transição normativo-legal, que passa a configurar estes grupos como detentores de direitos específicos. Tal transição tem seu marco com a promulgação da Constituição de 1988, que estabelece não somente um novo conceito que define estes grupos, mas que passa a reconhecer os remanescentes de quilombos como categoria social distinta. Tal avanço encontra-se ancorado na efervescência dos movimentos sociais que adentraram o cenário político brasileiro de forma mais incisiva a partir de 1970, tendo destaque as pautas endossadas pelo Movimento Negro, sendo os precursores das discussões em torno da temática quilombola.

Nesse contexto, a formação do movimento quilombola instituído em Minas Gerais se deu em 2005, com a criação da Federação das Comunidades Quilombolas do Estado de Minas Gerais (N'Golo), fruto de uma ampla cooperação entre instituições, pesquisadores e universidades. Estimulados pela promulgação do Decreto $\mathrm{n}^{\circ}$ 4.887/2003 (BRASIL, 2003a), diversas comunidades quilombolas adentraram as mobilizações em busca de reconhecimento e de acesso aos direitos básicos, sobretudo o acesso ao território.

Não obstante, a Educação tem se apresentado como importante pauta de discussão, uma vez que parte significativa das comunidades quilombolas no estado de Minas Gerais estão inseridas numa realidade de intensa vulnerabilidade social e de precarização dos serviços públicos, da qual a educação escolar não foge à regra. Apesar dos desafios enfrentados pelas comunidades no que tange ao acesso à educação, vale ressaltar os esforços construídos entre comunidades e coletivos sociais em prol de uma educação diferenciada que vise à formação de seus sujeitos. Neste sentido, vale apontar dois aspectos indispensáveis nas discussões em torno de uma proposta de Educação Quilombola: a) a existência de práticas educativas reproduzidas no interior das comunidades; e b) a influência do movimento quilombola na proposição de uma proposta escolar diferenciada. A observância destes aspectos foram elementos norteadores para o desenvolvimento da pesquisa que subsidia o presente artigo, resultado da confluência de nossa dissertação de mestrado e de nossa trajetória profissional junto ao movimento quilombola mineiro.

Ao longo de cinco anos de atuação em projetos sociais desenvolvidos em diversos territórios quilombolas, sobretudo nas regiões Norte, Rio Doce e Jequitinhonha, pudemos observar e acompanhar os processos de autorreconhecimento e de organização política de diversas comunidades, tendo no bojo de suas ações o acesso a direitos. Nesse processo, identificamos algumas distinções dentre as comunidades quilombolas visitadas em contextos sociais distintos, tendo em sua organização social, na manutenção de práticas culturais, na localização em área urbana ou rural e na participação política elementos de maior distinção. Pudemos observar que as comunidades que possuíam maior interação com o movimento social instituído eram mais organizadas e, de uma forma geral, preservavam aspectos relacionados a sua cultura tradicional e contavam com a participação de membros de todas as faixas etárias.

Dentre as inúmeras comunidades visitadas, a de Carrapatos da Tabatinga se destacava - e de distinguia das demais - sob alguns aspectos que descrevemos posteriormente. Tais questões, oriundas de uma observação ainda superficial, nos instigou a pesquisar os processos educativos reproduzidos no quilombo, tendo em suas formas cotidianas de educar aspectos basilares de sua formação identitária e de engajamento político.

Juntamente a esse processo, a aprovação das Diretrizes Curriculares Nacionais para a Educação Escolar Quilombola na Educação Básica (BRASIL, 2012) demarca o reconhecimento de uma proposta pedagógica a eles voltada, considerando as especificidades de suas formas de reprodução social, saberes e fazeres, indispensáveis à formação identitária dos sujeitos quilombolas. Contudo, para que a proposta alcance seus objetivos e ampla adesão entre seu público-alvo, torna-se necessário um diálogo, sendo a participação de lideranças, discentes e do movimento quilombola indispensáveis para uma efetiva implementação.

Diante do exposto, nosso intuito é o de contextualizar as contribuições dos coletivos sociais na elaboração de uma proposta educativa diferenciada, perpassando a educação popular, do campo, 
para então adentrarmos numa proposta voltada às populações quilombolas. À luz das observações coletadas em nossa pesquisa de campo e de nossas interlocuções no âmbito profissional junto ao movimento quilombola, apresentaremos alguns elementos que denotam a indissociabilidade entre os processos educativos reproduzidos nas comunidades e nas interações com o movimento. Ademais, vale ressaltar o papel que ambos desempenham na formação identitária de sujeitos quilombolas engajados, sendo esta uma etapa de suma relevância para pensarmos suas reivindicações no campo do direito, sobretudo o direito à Educação.

\section{A tomada de consciência: novas possibilidades de se educar}

Um novo clima cultural começa a se formar. [...] Um mundo novo se levanta diante deles, com matizes até então despercebidos. Ganham, pouco a pouco, a consciência de suas possibilidades, como resultado imediato de sua inserção no seu mundo e da captação das tarefas de seu tempo ou da visão nova dos velhos temas. Começam a fazer-se críticos e, por isso, renunciam tanto ao otimismo ingênuo e aos idealismos utópicos quanto ao pessimismo e à desesperança, e se tornam criticamente otimistas. (FREIRE, 2013, p. 74)

Iniciamos as discussões com uma citação de Paulo Freire, que, ao discutir em sua obra Educação como prática da liberdade, ${ }^{1}$ problematiza o momento de transição pelo qual passava a sociedade brasileira, no qual os sujeitos e grupos historicamente estigmatizados e excluídos do processo político-social-educativo adentram o cenário para trazer suas percepções e visões de mundo. Rompendo com aquilo que ele designa como alienação, desesperança e sentimento de inferioridade, os movimentos sociais passam a valorizar suas formas de viver, de produzir conhecimentos e, principalmente, sua cultura.

Concomitantemente às propostas que emergiam em torno de uma Educação Popular, as discussões em torno da Educação do Campo ganharam destaque junto aos coletivos sociais do meio rural, trazendo em seus discursos duas importantes perspectivas, indispensáveis à compreensão de tal

1 A primeira edição desta obra data de 1967. processo. A primeira característica consiste numa histórica desigualdade socioeconômica entre o homem do campo e o homem urbano, uma vez que o acesso a serviços públicos básicos apresenta uma significativa diferenciação entre os distintos contextos, não sendo diferente no que diz respeito à Educação. Já o segundo aspecto relaciona-se às diferentes formas de reprodução econômica e sociocultural identificadas no meio rural, sobretudo se considerarmos o acesso à terra.

Em Minas Gerais, o movimento pela Educação do Campo tomou corpo com a realização do I Encontro Estadual por uma Educação Básica do Campo, que ocorreu entre os dias 5 e 7 de junho de 1998, fruto da cooperação de diversas entidades vinculadas aos movimentos do campo. ${ }^{2} \mathrm{O}$ principal objetivo desse evento foi "discutir a problemática atual da escolarização rural e debater propostas visando construir as bases de um projeto educacional e político, a partir do campo, da realidade daqueles que moram e trabalham no meio rural, de sua cultura e experiências" (CENTRO DE DOCUMENTAÇÃO ELOY FERREIRA DA SILVA, 1998, p. 3). Apesar de não ter enfoque nos grupos tradicionais do campo, as discussões foram imprescindíveis para a formulação das propostas educacionais voltadas aos grupos étnico-raciais, uma vez que a grande maioria das comunidades remanescentes de quilombos está localizada em área rural.

As dinâmicas socioculturais do homem do campo perpassam por distintas formas de saberes e fazeres, as quais encontram-se ancoradas num vasto repertório demarcado pela tradicionalidade e ancestralidade desses grupos, que mantêm práticas oriundas das gerações que os antecedem. Ademais, o acesso aos meios de informação, à qualidade de vida, à inserção no mundo do trabalho e escolar, às relações familiares, às redes comunitárias, dentre tantos outros aspectos, resulta numa formação identitária específica, diretamente interligada à produção e subsistência agrícola e aos modos culturais que dela resultam. No campo educacional,

2 As instituições participantes responsáveis pela realização do evento foram: Movimento dos Sem Terra, Federação dos Trabalhadores na Agricultura do Estado de Minas Gerais (FETAEMG), Comissão Pastoral da Terra (CPT) e Associação Mineira das Escolas-Famílias-Agrícolas (AMEFA), além de representantes da Universidade do Estado de Minas Gerais (UEMG), Universidade Federal de Minas Gerais (UFMG) e professores das redes municipal e estadual de ensino. 
os sujeitos do campo trazem consigo seus valores e concepções de mundo, o que exige uma pedagogia diferenciada, que só se torna viável mediante utilização de instrumentos e linguagens condizentes com suas realidades.

Partindo de uma perspectiva freireana, o processo educativo deve considerar as vivências e experiências dos educandos em sua esfera social, uma vez que trazem consigo - e para a sala de aula - suas formas de interagir e interpretar o mundo, cabendo ao docente estabelecer trocas e formas de interação condizentes com a realidade de seus discentes. Nesse sentido, a Educação do Campo contribuiu para a desconstrução do paradigma de que o homem do campo, por ser, em sua maioria, analfabeto, era ignorante. Ora, talvez uma das maiores contribuições deste movimento foi o de considerar os diversos saberes tradicionais que estes indivíduos possuíam e que, portanto, deveriam ser mobilizados pedagogicamente.

Somadas às vozes do campo, as reivindicações do Movimento Negro contribuíram para a desconstrução da existência de uma pretensa igualdade de cunho racial no Brasil, endossada pelo mito da democracia racial. Aqui, nos importa destacar as contribuições dos coletivos negros na proposição de uma proposta educativa que contemplasse sua trajetória e suas contribuições socioculturais, a fim de desconstruir as desigualdades e racismos aos quais estes sujeitos estavam submetidos. A pesquisadora do Departamento de Pesquisas Educacionais da Fundação Carlos Chagas, Regina Pahim Pinto (1993, p. 28), reforça a relevância que a educação ganhou nos debates e nas mobilizações dos movimentos negros:

[...] De fato, se considerarmos o movimento negro como um indicador da atitude do negro, percebemos que a educação sempre esteve no centro das suas preocupações. Nas primeiras décadas do século, surgiram na cidade de São Paulo inúmeras associações negras que desenvolveram as mais diversas atividades educacionais. [...] Se antes o negro almejava simplesmente se educar, paulatinamente ele passa também a reivindicar do sistema educacional formal e da sociedade brasileira o reconhecimento de sua cultura, do seu modo de ser e de sua história.

Uma das mais significativas resultantes desse processo de mobilização no campo educacional foi a promulgação da Lei $\mathrm{n}^{\circ}$ 10.639/2003 (BRASIL, 2003b), que resultou na construção das Diretrizes Curriculares Nacionais para a Educação das Relações Étnico-raciais e para o Ensino de História e Cultura Afro-brasileira e Africana, em 2004, e do Plano Nacional de Implementação das Diretrizes Curriculares Nacionais para a Educação das Relações Étnico-raciais e para o Ensino de História e Cultura Afro-brasileira e Africana. Tais dispositivos trouxeram para a discussão curricular a representação do negro - e de sua herança enquanto importante matriz histórico-cultural constituinte do Brasil -, tendo em sua identidade etnicamente diferenciada um aspecto de extrema relevância no contexto educacional.

Resultante desse processo inicial, o movimento quilombola, amparado na Convenção 169 da Organização Internacional do Trabalho (OIT), ${ }^{3}$ aprova junto à Conferência Nacional de Educação (Conae) as Diretrizes Curriculares Nacionais para a Educação Escolar Quilombolas na Educação Básica (BRASIL, 2012), que destaca importantes elementos constitutivos a serem respeitados nos currículos escolares de escolas voltadas a este público específico, tais como:

da memória coletiva;

das línguas reminiscentes;

dos marcos civilizatórios;

das práticas culturais;

das tecnologias e formas de produção do trabalho;

dos acervos e repertórios orais;

dos festejos, usos, tradições e demais elementos que conformam o patrimônio cultural das comunidades quilombolas de todo o país;

da territorialidade. (BRASIL, 2012).

Parte desses aspectos pode ser identificada como constituinte dos processos educativos das comunidades quilombolas, os quais, alguns deles, pudemos

3 Convenção 169 da Organização Internacional do Trabalho (OIT) Sobre Povos Indígenas e Tribais, da qual o Brasil é signatário desde 2004. Dentre suas determinações, o direito autodeclaratório vinculado a uma identidade coletiva pode ser considerado o principal avanço, aliado às reivindicações do movimento quilombola, uma vez que pressupõe a autonomia destes grupos em se reconhecerem e se declararem enquanto remanescentes de quilombos. 
identificar na realização de nossa pesquisa junto à comunidade de Carrapatos da Tabatinga. Contudo, antes de adentrarmos na descrição de nosso campo e dos resultados de pesquisa, faz-se necessário apresentarmos algumas discussões que emergem de nossa interação com o movimento quilombola. Nosso intuito é identificar as contribuições desses coletivos na formação identitária dos sujeitos quilombolas, sendo esta etapa imprescindível no processo educativo e formativo dos indivíduos que se autodeclaram quilombolas, sobretudo lideranças.

\section{A experiência enquanto elemento transitório-formativo vivenciado junto ao movimento quilombola: um estudo de caso}

Como já descrevemos anteriormente, o movimento quilombola em Minas Gerais - contexto ao qual nos deteremos no presente trabalho - formalizou-se como principal entidade representativa das comunidades mineiras em junho de 2005, sob a razão social de Federação das Comunidades Quilombolas de Minas Gerais (N'Golo). Pudemos acompanhar parte da trajetória da entidade, quer de forma presencial, quer por meio das narrativas daqueles que participaram ativamente de sua formação. Tal experiência se deu mediante participação como colaboradores da N'Golo junto aos eventos de articulação política, mobilizações regionais e na organização do V Encontro Estadual de Comunidades Quilombolas de Minas Gerais, em 2012, mediante atuação profissional na ONG Cedefes. ${ }^{4}$

Ao longo de nossa experiência profissional, dois momentos se distinguem, a fim de contribuir para as reflexões que aqui nos propusemos a desenvolver. A primeira se relaciona ao acompanhamento da agenda de lideranças da N'Golo, sobretudo aquelas junto aos setores públicos, quer na construção de projetos e parcerias, quer na discussão de políticas públicas para o público em questão. Já o segundo momento faz referência ao processo de elaboração

4 Atuação profissional como Técnica de pesquisa do Projeto "Quilombos Gerais" (2011-2013) e como Coordenadora Executiva dos projetos "Promoção e Desenvolvimento de Agentes Quilombolas Socioambientais no Médio Jequitinhonha" e "Agentes Quilombolas Socioambientais: o turismo como geração de renda no Médio Jequitinhonha" (2013-2015) junto ao Centro de Documentação Eloy Ferreira da Silva (Cedefes). de uma revista publicada pelo Cedefes, que resultou num diagnóstico acerca das comunidades quilombolas em Minas Gerais. Em ambas as experiências pudemos captar narrativas, discussões e trocas de experiências entre lideranças quilombolas, sobretudo no que diz respeito à sua inserção no movimento quilombola instituído. Uma fala recorrente entre eles diz respeito às mudanças observadas e vivenciadas por cada um após adentrar o movimento, $\mathrm{o}$ que denota o aspecto formativo do movimento em si, sendo parte das percepções acerca do movimento e da construção identitária definida nestes espaços.

Vale ressaltar que um dos elementos que endossaram nossa escolha pela comunidade de Carrapatos da Tabatinga para nossa pesquisa de dissertação de mestrado foi a significativa participação de seus membros na N'Golo e no movimento quilombola de âmbito nacional. Atuantes desde as primeiras mobilizações, as lideranças da comunidade ganharam destaque e atualmente são tidas como referências para as demais lideranças e comunidades quilombolas. A principal figura política da comunidade, Sandra Maria da Silva, foi presidente da N'Golo por dois mandatos consecutivos (20112015), além de ser a representante do estado de Minas Gerais na Conaq. ${ }^{5}$

Partindo do pressuposto de que os processos educativos somente são possíveis por meio da experiência de seus sujeitos, compreendemos que todo grupo humano tem a necessidade de transmitir sua experiência acumulada às novas gerações, a fim de que sejam perpetuadas no presente, o que explicaria a relação tênue entre processos educativos e experiências. Nesse sentido, o movimento quilombola torna-se espaço de trocas, de solidariedade e de compartilhamento das experiências individuais (comunitárias) que, apesar de suas individualidades, encontram um ponto comum entre elas: a exclusão.

A exclusão pode ser considerada fator determinante na formulação de pedagogias próprias e da proposição de pautas relacionadas às demandas sociais vivenciadas pelos grupos historicamente invisibilizados ao longo de nossa história. Na contramão de uma proposta educacional hegemônica,

5 ACoordenação Nacional de Articulação das Comunidades Negras Rurais Quilombolas (Conaq) é a principal entidade representativa quilombola em âmbito nacional, contando com a filiação de todos os estados brasileiros que possuem comunidades remanescentes de quilombos. 
esses grupos, organizados, propõem uma forma de se educar baseada em suas referências históricas e culturais, nas especificidades étnicas e nas práticas cotidianas, tendo por referência as desigualdades nas quais se veem imersos. Todo esse repertório, baseado numa experiência de grupo/classe, endossa os discursos proferidos nas mobilizações, o que, consequentemente, reflete na pauta do movimento por educação. Arroyo (2012) aponta que os padrões de poder/saber se constituíram no intuito de inferiorizar os coletivos sociais, o que estimulou a elaboração de formas próprias de se constituir o pensamento sociopedagógico.

Orientados pela tradicionalidade, pela memória coletiva e pelas experiências de luta das diversas comunidades, em seus respectivos contextos, os coletivos sociais propõem um projeto educativo amplo, que enfoque suas realidades por meio da valorização de uma educação associada às reivindicações materiais e de condições básicas de vida. Nesse sentido, Miguel Arroyo (2012, p. 79) descreve que:

O objeto das mobilizações são necessidades localizadas no seu universo mais próximo, na reprodução mais imediata da existência, porém as reivindicações são dirigidas para fora, para os governos, para as políticas públicas, para a reforma agrária, para o modelo econômico, para a igualdade, para a escola e as universidades. Para outro projeto de sociedade. Os movimentos sociais e juvenis geram um saber de si e um saber-se para fora. Um saber político que alarga seu saber local e se amplia. Os sujeitos que participam nesses movimentos vão sendo munidos de interpretações e de referenciais para entender o mundo fora, para se entender como coletivo nessa 'globalidade'. São munidos de saberes, valores, estratégias de como enfrentá-lo. Conscientes dos limites para superá-los.

Em suma, as reivindicações e demandas trazidas pelos coletivos sociais derivam das experiências das comunidades, resultantes dos desafios que elas enfrentam em torno da sustentabilidade, da luta pela terra e/ou da reprodução sociocultural (tradição). $\mathrm{O}$ que vale demarcar neste momento é o papel que a experiência possui em tal processo, sendo no fazer, no ensinar-fazendo, que os saberes são absorvidos de uma forma efetiva, culminando na constituição de sujeitos politicamente engajados.
A experiência quilombola diz também de todo um histórico de ausências de políticas e investimentos em infraestrutura, sobretudo na área educacional, o que pode ter sido um estímulo para se criar formas próprias de se educar. Para além do acesso à educação formal, as comunidades quilombolas do estado ainda enfrentam o silenciamento de suas especificidades e buscam ser representadas no currículo escolar vigente. Tal situação torna-se ainda mais agravante se considerarmos os municípios que possuem comunidades quilombolas, mas que são praticamente desconhecidas enquanto tais pela gestão municipal e pela população local.

Consequentemente, as experiências que emergem das mobilizações quilombolas são indispensáveis para a construção de um modelo de educação quilombola, em resposta às suas demandas. Experiência que advém de uma vivência, de uma construção de sentido na prática, descrita por Jorge Larrosa (1994, p. 02) "como o que nos passa, o que nos acontece, o que nos toca". Sendo assim, o processo de conscientização destes sujeitos enquanto quilombolas diz de um processo reflexivo, crítico e político, que revela as dimensões de uma série de elementos e signos que contemplam as perspectivas de ser quilombola. A assimilação dos sujeitos à trajetória e identidades coletivas somente é possível a partir de uma consciência individual, de uma experiência de si.

As trocas culturais e a transmissão dos saberes e fazeres são de suma relevância neste processo, uma vez que a experiência, o "passar por", representa uma pedagogia que não pode ser aprendida no espaço da escola, por exemplo. Essa formação totalizante do sujeito somente é possível na vivência em comunidade, uma vez que condiz às subjetividades, àquilo que se relaciona aos sentimentos, à identidade, aos valores morais e à etnicidade do grupo.

Partindo das experiências relatadas pelos quilombolas de Carrapatos da Tabatinga acerca de sua própria experiência, sobretudo com o movimento quilombola, é possível afirmar que estes sujeitos tornam-se quilombolas a partir do momento em que se apropriam politicamente do significado de "ser quilombola". Em diversos momentos, a liderança mais atuante da comunidade, Sandra Maria, relata que, ao se aproximar das primeiras mobilizações do movimento quilombola estadual, 
Não sabia nem como me comportar, eu tinha vergonha e medo de tudo. Eu ficava que nem bicho do mato, quietinha num canto, só escutando o que os outros quilombolas que estavam há mais tempo falavam. Eu agarrava no braço do Jésus (companheiro de movimento) e ficava prestando atenção no que aquele povo tava dizendo. Eu não sabia de nada, nem sabia que a gente tinha direito. Aos poucos fui aprendendo e me soltando mais. (SANDRA MARIA, 54 anos).

Ao tomarmos o breve relato de Sandra, é possível notar o antes e o depois de sua experiência, sendo sua trajetória no movimento quilombola um processo formativo, que perpassou sua experiência de si enquanto quilombola. A geração que deu início a uma articulação voltada à temática quilombola na comunidade teve seu processo de consciência de si a partir do conhecimento e da experiência junto ao movimento, sendo perceptíveis falas e comportamentos bastante marcados, reflexo de suas experiências. Este fenômeno é descrito por Brandão e Assumpção (2009) como uma educação popular diretamente vinculada a uma tradição quilombola, uma pedagogia dialógica, uma vez que se baseia nas trocas (experiência) entre sujeitos e na transmissão oral. Para esses autores, a educação popular pode ser entendida como um trabalho coletivo, ou seja, é o momento em que "a vivência do saber compartilhado cria a experiência do poder compartilhado" (BRANDÃO; ASSUMPÇÃO, 2009, p. 35).

Ao perguntarmos "O que você acha que mudou na sua vida depois que você começou a ser um militante da causa quilombola?", a experiência também aparece como importante traço na narrativa de outra liderança da comunidade:

Mudou muito, porque através dessa militância eu vi o quanto que a gente pode mudar a consciência nossa mesmo e de quem tá ao redor da gente. Fácil não é não, mas que a gente pode mudar muita coisa, correr atrás de muita coisa, conseguir muita coisa, através da união. E, como se diz... o movimento... [pausa de dois segundos] muita gente pensa que quando a gente tá no movimento a gente quer buscar as coisas só pra gente, e não é. A gente quer buscar pro bem comum. E se a gente der as mãos e lutar junto, a gente consegue fazer pra gente e pra todos que tá ao nosso redor. (TÂNIA, 54 anos).

Ao longo de nossa inserção profissional, em que pudemos acompanhar de perto lideranças qui- lombolas que compunham a N'Golo, identificamos diversos elementos que demarcaram a trajetória desses indivíduos nos movimentos. Parte desses relatos encontram-se numa cartilha produzida pela ONG Cedefes - a qual pudemos organizar ${ }^{6}-$, de onde extraímos dois fragmentos que descrevem parte dessa experiência:

Nasci na comunidade de Mumbuca. Meu pai era carreteiro de bois, também fazia caixão para enterrar morto. É bom trabalhar em comunidade, mas é difícil! Eu queixo porque não estudei mais. Queria estudar mais, mas meu pai não deixou. Depois que comecei a participar da N'Golo aprendi muito. Hoje tenho mais informações sobre a questão quilombola em Minas e no Brasil, tenho mais conhecimento e as coisas começaram a acontecer na minha vida. (JOÃO DA CRUZ BISPO). (CENTRO DE DOCUMENTAÇÃO ELOY FERREIRA DA SILVA, 2013, p. 31-32).

Assim, o que aprendi na minha comunidade me preparou para participar da N'Golo. Quero sempre fazer parte dessa história de luta pelos direitos quilombolas em Minas Gerais. Juntos construímos uma história, juntos podemos mudar nosso futuro. Podemos participar da escrita de uma nova história em Minas Gerais. (JESUS ROSÁRIO ARAÚJO). (CENTRO DE DOCUMENTAÇÃO ELOY FERREIRA DA SILVA, 2013, p. 33).

Ao utilizarmos parte das narrativas de duas lideranças quilombolas - que atuaram ativamente no processo de formação da N'Golo -, identificamos dois aspectos importantes: a relação direta com movimento e a percepção de luta e sua conscientização de uma identidade pós-movimento. O movimento que percebemos é o da experiência desses sujeitos, o de apropriação de um conhecimento acerca de si, de suas identidades e de seus direitos, individuais e coletivos. Aqui, temos dois agricultores rurais que relatam seu processo de "estar no mundo", de valorização, da construção de sua autoestima. O aprendizado adquirido no movimento contempla e valoriza as diversas subjetividades e questões materiais indispensáveis à vivência e manutenção comunitária, nas quais as formas de saberes e fazeres quilombolas encontram-se ancoradas.

6 Cartilha intitulada Comunidades Quilombolas de Minas Gerais: entre direitos e conflitos, que apresenta resultados do projeto trienal "Quilombos Gerais", lançada em 2013 pelo Centro de Documentação Eloy Ferreira da Silva. 
Partindo do pressuposto de que as comunidades quilombolas possuem formas diferenciadas de reprodução sociocultural, podemos concluir que suas formas de educar também devem contemplar tais diferenciações, o que tornam legítimos os demais espaços de formação e de propostas pedagógicas voltadas aos seus sujeitos. Nesse sentido, os movimentos sociais representam um espaço de valorização de sua cultura diferenciada e de conscientização dos sujeitos quilombolas, rompendo com estruturas homogeneizantes e excludentes às quais esses grupos estiveram submetidos ao longo do processo histórico. O que os movimentos sociais propõem são experiências que visam a superação de exclusões, havendo aqui um importante processo de transformação social, uma vez que: "A visibilidade da experiência se torna então evidência para o fato da diferença, em vez de se tornar uma forma de explorar como a diferença é estabelecida, como ela opera, e como e de que maneira constitui sujeitos que veem e atuam no mundo" (SCOTT, 1998, p. 302).

A tomada de consciência acerca de si, de seu lugar enquanto sujeito social e de ocupar um lugar de desigualdade numa conjuntura ampla emerge de uma relação oprimido/opressor, ao qual Paulo Freire traz contribuições de suma importância no âmbito educacional. A inserção junto aos movimentos pode ser considerada o momento de transição do quilombola para o sujeito político, detentor de direitos, consciente de sua trajetória de exclusão e da necessidade da luta. Aqui, a educação pode ser entendida como uma forma de expressão da liberdade, de ruptura com uma hegemonia que aliena os grupos sociais invisibilizados.

Por meio da transmissão de suas lutas e filosofias de vida a educação proposta pelos movimentos ganha forma, se concretiza como proposta educativa efetiva, indispensável à manutenção de suas formas próprias de viver. Mais do que uma influência, os movimentos sociais são os principais responsáveis pela conquista de propostas educativas específicas. Todo este processo deve ser considerado e valorizado enquanto um importante mérito dos movimentos, a fim de descontruir estereótipos negativados acerca dos quilombolas, tidos como desorganizados e "marginalizados" pelo senso comum.
As conquistas do movimento quilombola no que tange à Educação Escolar Quilombola ainda são pouco mensuráveis, uma vez que as diretrizes específicas são recentes, além da pouca efetividade ao implementar tal política de forma abrangente. À luz do MST, obtemos uma compreensão mais ampla acerca do acesso à Educação como uma estratégia de luta do movimento, uma vez que congrega inúmeras experiências bem-sucedidas de uma educação diferenciada:

A escola é vista como um espaço onde crianças e adolescentes estão se formando como seres humanos integralmente. Assim, ela não é lugar de 'aprendizagem apenas teórica', mas lugar de 'estudo e trabalho'. A escola deve se somar no objetivo de construir sujeitos da história, portanto deve formar a 'consciência e a capacidade de ação', a partir dos interesses da classe trabalhadora. A organização coletiva também possui na proposta analisada um valor educativo fundamental, pois é ela que permite superar a atual forma de sociedade e é capaz de gerar a consciência de classe. (VENDRAMINI; MACHADO, 2011, p. 46 , grifo do autor).

Nessa perspectiva, podemos afirmar que os sujeitos quilombolas possuem uma nítida compreensão de que, diante de uma histórica exclusão, o acesso a direitos, incluindo a Educação, somente será concretizado por meio de lutas e reivindicações bem alinhadas entre si.

\section{As relações entre observador- observado: questões metodológicas}

As interações entre pesquisadores e pesquisados teve início ainda durante nossa trajetória profissional, o que gerou reflexos positivos para o alcance dos resultados da pesquisa. A descrição deste processo torna-se importante para compreendermos os desafios e as possibilidades que a pesquisa de campo nos impõe, além de atestar a inexistência de uma "neutralidade" do pesquisador ao observar seus sujeitos. Ao contrário, este processo também se torna formativo e dinâmico, cabendo ao pesquisador adequar todos os conceitos teórico-metodológicos apreendidos anteriormente, para com eles dialogar e adaptá-los às questões de campo. Nossa experiência atesta que os roteiros nada mais são do que norteadores iniciais, que 
vão sendo reformulados de acordo com aquilo que observamos em campo ao longo de nossa inserção na comunidade.

Nossa pesquisa buscou seus subsídios no método etnográfico sem, contudo, se caracterizar como tal, sendo uma opção por nós adotada ao longo da pesquisa. Sob a perspectiva de dar voz aos sujeitos pesquisados - a fim de identificar a autopercepção enquanto quilombolas -, os separamos em três grupos específicos: a) lideranças adultas que participam ativamente do movimento quilombola; b) jovens e adolescentes; c) a matriarca e principal referência da comunidade. Para tanto, lançamos mão dos seguintes métodos de pesquisa: a observação participante (ANGROSINO, 2009); entrevista centrada no problema (RIBEIRO, 2008); narrativa (FLICK, 2009); análise de dados visuais; e triangulação de dados (ALVES-MAZOTTI; GEWANDSNAJDER, 2004), a fim de captar na subjetividade cotidiana as formas de educar desses sujeitos. Vale dizer que a pesquisa se deteve a observar dois espaços distintos: o núcleo familiar de Dona Sebastiana, a matriarca da comunidade, e os espaços de articulação política representados pelo movimento social quilombola.

Ao fazermos referência à convivência em nossa prática enquanto pesquisadores, estamos nos referindo à construção de confiança, fator que julgamos ser imprescindível na condução de uma pesquisa orientada pela etnografia, o que, a nosso ver, só é possível adquirir mediante trocas e vivência com os sujeitos da pesquisa. O "fazer com eles" foi de suma importância para percorrermos espaços e atividades que somente os membros da família se viam autorizados a participar, o que contribuiu significativamente para a coleta do material oriundo das observações de campo.

Vale ressaltar que, durante todo o processo de pesquisa de campo, ficamos hospedados na casa da liderança Sandra, local que é uma importante referência para a comunidade, uma vez que ela reside no mesmo lote em que a associação comunitária quilombola está localizada. Nesse sentido, participamos de forma ativa da vivência em comunidade, captando situações e interações bem interessantes, tendo à nossa disposição nosso "objeto" quase que em tempo integral. Durante as observações, o único material utilizado foi o caderno de campo, o que, de certa forma, neutralizava nossas incursões, não causando maior estranhamento, e, ao mesmo tempo, nos permitia pontuar questões importantes que eram captadas naquele momento.

Para a realização das entrevistas, dividimos os questionários em duas versões: uma para os jovens e outra para as lideranças adultas da comunidade, uma vez que um de nossos objetivos foi captar as distintas percepções acerca do "ser quilombola" sob o recorte geracional, como mostra o Quadro 1.

Quadro 1 - Dados dos membros da comunidade entrevistados

\begin{tabular}{|l|c|c|c|l|}
\hline \multicolumn{1}{|c|}{ Nome } & Idade & Sexo & Escolaridade & \multicolumn{1}{c|}{ Atuação junto ao movimento quilombola } \\
\hline $\begin{array}{l}\text { Cleverson Luiz } \\
\text { Epifânio de Oliveira }\end{array}$ & 23 & $\mathrm{M}$ & $\begin{array}{c}\text { Cursando } \\
\text { Superior }\end{array}$ & $\begin{array}{l}\text { Festividades da comunidade e eventos do movimento } \\
\text { quilombola em âmbito local e estadual }\end{array}$ \\
\hline $\begin{array}{l}\text { Laura Gabriele } \\
\text { Januária }\end{array}$ & 12 & $\mathrm{~F}$ & $\begin{array}{c}\text { Cursando } \\
\text { Fundamental }\end{array}$ & $\begin{array}{l}\text { Movimento de juventude quilombola, festividades da } \\
\text { comunidade e reuniões do município }\end{array}$ \\
\hline $\begin{array}{l}\text { Maria das Graças } \\
\text { Epifânio da Silva }\end{array}$ & 43 & $\mathrm{~F}$ & $\begin{array}{l}\text { Ensino Médio } \\
\text { completo }\end{array}$ & $\begin{array}{l}\text { Conselho Municipal da Criança e Adolescente, } \\
\text { Conselho Municipal de Saúde, N'Golo, Conaq, } \\
\text { Associação Quilombola e festividades da comunidade }\end{array}$ \\
\hline $\begin{array}{l}\text { Silvio Gabriel } \\
\text { Januário }\end{array}$ & 15 & $\mathrm{M}$ & $\begin{array}{c}\text { Cursando } \\
\text { Ensino Médio }\end{array}$ & $\begin{array}{l}\text { Mobilizações de juventude local, Conferências e } \\
\text { encontros quilombolas de âmbito estadual e nacional }\end{array}$ \\
\hline $\begin{array}{l}\text { Tânia Aparecida da } \\
\text { Silva Oliveira }\end{array}$ & 53 & $\mathrm{~F}$ & $\begin{array}{l}\text { Ensino Médio } \\
\text { incompleto }\end{array}$ & $\begin{array}{l}\text { Conselho Municipal de Saúde, Conselho Municipal } \\
\text { da Mulher, Conselho Estadual de Promoção da } \\
\text { Igualdade Racial, Conselho Estadual de Alimentação } \\
\text { Escolar, Associação Quilombola, N'Golo e Conaq. }\end{array}$ \\
\hline
\end{tabular}

Fonte: Elaborado pelos autores deste artigo. 
As perguntas estavam ancoradas em questões basilares, as quais buscavam analisar os seguintes eixos básicos da pesquisa:

- A percepção que os sujeitos da pesquisa têm acerca do sentido de quilombo;

- O conhecimento acerca da história de formação e valores de sua comunidade;

- O grau de engajamento e atuação e de que forma compreendem o movimento quilombola;

- De que forma concebem seu lugar enquanto sujeitos, o acesso a direitos e à cultura diferenciada enquanto remanescentes de quilombos.

Por fim, selecionamos apenas cinco entrevistas para compor a pesquisa, uma vez que priorizamos o uso de outras fontes de coleta, a fim de estabelecer um diálogo analítico-comparativo entre eles, uma vez que:

À medida que os dados vão sendo coletados, o pesquisador vai procurando ativamente identificar temas e relações, construindo interpretações e gerando novas questões e/ou aperfeiçoando as anteriores, o que, por sua vez, o leva a buscar novos dados, complementares ou mais específicos, que testem suas interpretações, num processo de "sintonia fina" que vai até a análise final. (ALVES-MAZZOTTI; GEWANDSZNAJDER, 2004, p. 170).

Ademais, acompanhamos a Guarda de Moçambique, principal manifestação cultural de matriz africana da comunidade, durante a Festa de São Benedito, em 2015. Para além do espaço da comunidade, pudemos acompanhar algumas de suas lideranças nos espaços de formação e de articulação política, tanto em âmbito estadual (agenda da N'Golo) quanto em articulações em Brasília (agenda da Conaq), com enfoque na liderança Sandra Maria. Nessa etapa foi possível obtermos um comparativo entre a vida cotidiana em comunidade e sua atuação como liderança política, além dos aspectos presentes em suas narrativas nos distintos espaços. Nesse sentido, a observação participante em ambos os espaços nos auxiliou na triangulação e na análise dos dados coletados em campo, uma vez que pudemos acompanhar dois momentos distintos dessas referências comunitárias. Por fim, utilizamos narrativas registradas em dois audio- visuais: A Filha de São Sebastião (A FILHA..., 2014) e Dandaras: a força da mulher quilombola (DANDARAS..., 2015).

\section{Das narrativas ao discurso}

Ao analisarmos as discussões que vimos fazendo até aqui acerca dos processos educativos reproduzidos entre os remanescentes de quilombos, quer no interior das comunidades, quer no seio dos movimentos sociais, é possível afirmar que tais processos são orientados e construídos como estratégias de sobrevivência e de reivindicações políticas. No caso da comunidade de Carrapatos da Tabatinga, em específico, o processo formativo encontra-se diretamente ligado à inserção e à trajetória de seus sujeitos nos movimentos sociais, sendo estes importantes espaços de formação daquilo que vimos designando "ser quilombola". Neste processo de constituição e de afirmação de uma identidade propriamente quilombola, encontramos um aspecto de suma relevância e que tem por função orientar todo este processo de transmissão dos saberes e ideologias: a palavra.

Manifesta de formas diferentes, do cotidiano em comunidade aos momentos de mobilização, a palavra é o principal instrumento e meio pelo qual todo o conjunto de crenças, concepções, reivindicações, saberes e valores é transmitido de geração em geração. Nesse sentido, faz-se necessário analisarmos as formas diferentes que a palavra assume nos diferentes espaços, sendo possível demarcarmos dois aspectos principais em que ela se manifesta: nas narrativas e no discurso. Vale ressaltar que tanto a narrativa quanto o discurso cumprem funções complementares, sendo o principal veículo de construção social e de formação dos sujeitos quilombolas, perpassando das relações familiares até as mais distintas formas de mobilização social.

Para além da nítida manifestação da experiência nesse processo, as trocas estabelecidas entre o narrador e seus ouvintes pressupõem um processo educativo manifesto na fala e na escuta entre os sujeitos, o que representa uma estratégia pedagógica de grande valia. Para Rosário (1989), toda narrativa incorpora quatro elementos básicos que se relacionam à vida em comunidade: a) aspectos 
geográficos; b) aspectos econômicos; c) aspectos sociológicos, culturais e etnográficos; e d) aspectos mágico-religiosos. Partindo do pressuposto de que as narrativas são produzidas à luz das comunidades que as produzem, há de se considerar que este processo constitui um fenômeno organizado, articulado entre seus sujeitos, a fim de garantir a manutenção das memórias e histórias relevantes. Nesse sentido, as narrativas cumprem uma importante função, já que:

Além disso, sabemos que a narrativa funciona como registo que documenta a sobrevivência de usos, costumes, fórmulas jurídicas, valores morais e sociais vigentes ou esquecidos pelo tempo. Aliás a ilogicidade que muitas vezes é patenteada por algumas sequências narrativas não passa de uma reminiscência de valores a nível do universo narrativo que há muito desapareceram da história. A narrativa oral é um tecido complexo que busca a sua formação através da fusão de elementos regionais, representados pelo narrador, da história e geografia locais bem como da linguagem actual e com elementos universais representados pelos temas, pelos valores colectivos quer morais quer culturais e pela obediência a uma estrutura esquemática herdada. (ROSÁRIO, 1989, p. 95).

No caso da comunidade pesquisada, é possível afirmar que as narrativas são indissociáveis das práticas educativas e da formação política dos sujeitos quilombolas, tendo como figura central a matriarca da comunidade, Dona Sebastiana. Considerando o processo migratório ao qual a comunidade foi submetida na década de 1970, o registro acerca de sua origem, da luta e dos costumes de seus ancestrais se faz presente na memória coletiva do grupo mediante o uso das narrativas.

No conjunto dos discursos entoados pelos movimentos sociais, o estabelecimento de signos que os identifique enquanto categoria específica somente é concretizado à luz de uma função ideológica. $\mathrm{O}$ filósofo russo Mikhail Bakhtin (2009) analisa de forma descritiva - e em detalhes - os processos de construção dos signos e de sua assimilação entre sujeitos e grupos sociais, afirmando existir uma interação dialética entre psiquismo e ideologia. Para o autor, o signo ideológico percorre ambos os campos, fenômeno social que perpassa a constituição sociológica dos sujeitos, quer no âmbito individual, quer em sua formulação coletiva. Nessa perspectiva, este autor compreende que:

O indivíduo enquanto detentor dos conteúdos de sua consciência, enquanto autor de seus pensamentos, enquanto personalidade responsável por seus pensamentos e por seus desejos, apresenta-se como fenômeno puramente socioideológico. Esta é a razão por que o conteúdo do 'psiquismo' individual é, por natureza, tão social quanto a ideologia e, por sua vez, a própria etapa em que o indivíduo se conscientiza de sua individualidade e dos direitos que pertencem é ideológica, histórica, e internamente condicionada por fatores sociológicos. Todo signo é social por natureza, tanto o exterior quando o interior. (BAKHTIN, 2009, p. 59).

Resultantes de um processo de conscientização dos sujeitos, os discursos dos grupos quilombolas tornam-se parte do processo formativo de seus sujeitos, tendo nas narrativas sua base de sustentação. No caso quilombola, parte das narrativas que remetem ao período escravista são legitimados nos discursos que têm por finalidades o reconhecimento e a valorização desses grupos no âmbito das políticas públicas. É bastante comum o uso de fragmentos de suas histórias e a contextualização acerca das desigualdades produzidas pela colonização nos espaços de mobilização política. Numa relação que perpassa a subjetividade dos sujeitos e é colocada de forma implícita, a conversão das narrativas históricas em discursos políticos é uma estratégia que não pode ser desprezada, uma vez que nos revela parte do processo educativo do grupo em questão.

Sendo assim, concluímos que a ideologia forma o sujeito político e imbuído de uma consciência identitária, sendo parte indispensável à formação do "ser quilombola", condição esta que não é orgânica, mas construída ao longo de suas vivências e interações comunitárias e intergrupais. Apesar da dificuldade em determinar um marco temporal neste processo de conscientização e de construção ideológica, no caso mineiro é possível demarcar a formação da N'Golo, em 2005, como um importante marco. Anterior à uma organização política enquanto movimento instituído, os remanescentes de quilombolas perpassavam por movimentos distintos, não sendo possível identificar um discurso unificado e que representasse a categoria quilombola. 
A adoção e a reprodução de um discurso em torno de uma identidade quilombola só é possível graças a uma consciência enquanto parte de um grupo e aos seus códigos culturais. Dessa forma, antes de endossar um discurso coletivo, reproduzido pelos movimentos sociais, os sujeitos assimilam parte destes signos ainda em sua vivência na comunidade, sendo este um importante aspecto dos processos educativos. Portanto, é possível associar (afirmar) a relação entre os processos educativos apreendidos no interior das comunidades e seus reflexos nos discursos junto ao movimento quilombola, sendo um resultante do outro. No caso de Carrapatos da Tabatinga - mediante narrativas coletadas durante a pesquisa de campo -, os sujeitos já detinham uma consciência acerca de suas "diferenças" antes mesmo de terem contato com o termo remanescentes de quilombos. Segundo as narrativas da liderança Sandra Maria, "quando conheci o que era quilombola, tudo fez sentido, reconheci minha comunidade".

\section{Os elementos presentes nas formas de se educar no quilombo: observações da comunidade quilombola de Carrapatos da Tabatinga}

A fim de compreender os elementos que compõem os processos educativos e a formação identitária dos sujeitos que se autoidentificam como quilombolas é que a pesquisa foi desenvolvida junto à comunidade quilombola de Carrapatos da Tabatinga. Localizada na região centro-oeste mineira, na área urbana do município de Bom Despacho, a referida comunidade foi escolhida por reunir alguns aspectos que se diferenciam de outras comunidades quilombolas com as quais pudemos interagir ao longo de nossa inserção no Cedefes. Dentre os elementos que previamente nos despertaram, vale ressaltar os que mais nos interessam para o presente estudo de caso:

a) Apesar de estar localizada em área urbana, a comunidade ainda preserva aspectos organizacionais que raramente são identificados em quilombos inseridos em contexto semelhante, tais como a vida em comunidade, a manutenção da uma religiosidade de matriz africana, manifestações culturais específicas, dentre outras; b) O papel aglutinador desempenhado pela figura da matriarca, principal responsável pela manutenção dos aspectos tradicionais do grupo, sendo o principal elo entre passado e presente, o qual se manifesta pela retomada da memória coletiva dos antepassados e da história de resistência da comunidade;

c) A oralidade é a principal forma de transmissão de memória e dos saberes e fazeres que são reproduzidos na atualidade pelos seus sujeitos;

d) Parte significativa das lideranças da comunidade, sobretudo mulheres, são atuantes nos movimentos quilombolas de âmbito estadual e nacional, sendo importantes referências, legitimadas pelas demais comunidades do estado;

e) A participação de jovens nas mobilizações políticas voltadas à temática quilombola $\mathrm{e}$ da juventude quilombola é um aspecto de destaque, uma vez que suas experiências vão na contramão de outras comunidades, que têm sofrido com a baixa adesão da juventude nas manifestações culturais e na organização política.

Diante de tais aspectos, emergiu nosso interesse em desenvolver uma pesquisa na área da Educação Quilombola, uma vez que partimos do pressuposto de que estes e demais aspectos são parte fundante dos processos educativos das comunidades quilombolas. Nesse sentido, dois preceitos são de suma relevância para compreendermos a educação quilombola enquanto proposta curricular e pedagógica específica: a) as comunidades quilombolas possuem formas próprias de educar seus sujeitos, transmitindo valores e saberes indissociáveis de sua tradicionalidade; b) as formas de se educar nos quilombos, juntamente com seus valores norteadores, devem ser consideradas na elaboração de uma modalidade de educação escolar quilombola.

Antes de adentrarmos aos elementos presentes no processo educativo identificados na comunidade pesquisada, vale destacar os procedimentos e métodos adotado na sua condução, a fim de justificar as conclusões que apresentaremos ao término deste trabalho. A pesquisa qualitativa buscou suas referências na etnografia, apropriando-se de alguns preceitos básicos que nos nortearam na condução 
das imersões no campo de pesquisa. Apesar da complexidade e da diversidade dos elementos coletados em campo ao longo da pesquisa, nos deteremos a somente elencar alguns dos aspectos - ainda de que forma resumida - identificados no processo educativo, enquanto um estudo de caso.

Os aspectos formativos que compõem aquilo que designamos tradicionalidade quilombola são o ponto de partida na identificação das formas de se educar e formar sujeitos quilombolas engajados e que se identificam com uma identidade etnicamente diferenciada. Tais aspectos são encontrados, sobretudo, nos discursos e narrativas entoados tanto nos espaços de trocas cotidianas da comunidade, quanto nos espaços de formação política promovidos pelos coletivos sociais. Parte desses elementos denotam uma relação direta com as matrizes africanas, o que reforça as reminiscências do período escravista, reconfiguradas e adaptadas pelas comunidades no contexto atual, sendo um dos aspectos que comprovam sua trajetória com a escravização. A seguir, apresentaremos, de forma sintética, alguns destes aspectos.

\section{Identidade}

Ao discutirmos a cultura e seu papel no processo de reconhecimento dos povos e comunidades tradicionais, deparamo-nos com o conceito de identidade, uma vez que um depende do outro na constituição político-ideológica dos sujeitos e dos grupos sociais específicos. Nesse sentido, podemos afirmar que as identidades são concebidas a partir da concepção da diferença, o que, para Tomaz Tadeu da Silva (2014), emerge através dos sistemas simbólicos e pelas formas de exclusão social, afirmando que a identidade depende da diferença.

Emergindo das relações híbridas, orientadas pelas disputas entre "nós" e os "outros", a questão da identidade emerge enquanto questão ideológica, de disputa sociopolítica, sendo orientada por questões históricas. Esta tensão é de extrema relevância na construção identitária, uma vez que a concepção da existência de uma comunidade imaginada é um dos pilares das representações culturais de cada grupo em específico. Para Hall (2009, p. 81), "toda identidade é fundada sobre uma exclusão", o que nos aponta os conflitos em torno das relações sociais, pelas quais as relações de poder são constituídas.

Entretanto, do ponto de vista antropológico, a questão da identidade torna-se bastante sensível, uma vez que se localiza num espaço de transição, não sendo estática, imobilizada pela história. Pelo contrário, a identidade somente pode ser concebida como aspecto de análise mediante a observância de que é simbólica, tomando conotação política pelos sujeitos de determinados grupos que recorrem a ela enquanto instrumento de reconhecimento e legitimidade cultural.

Os valores e crenças que passam a constituir a identidade de determinado grupo são negociados socialmente, sendo este um processo dinâmico, que pode variar segundo o período histórico e as tensões que dele advêm. Partindo da ideia de remanescentes de quilombos, este fator torna-se ainda mais perceptível, uma vez que não é incomum identificar processos de "resgate" de práticas há muito fragmentadas nas comunidades que, mediante emergência de políticas específicas, passaram a ressignificar inúmeras práticas do cotidiano das comunidades. Não seria exagero dizer que o reconhecimento legal das populações quilombolas enquanto sujeitos de direito influenciou significativamente o processo de (des)invisibilização de inúmeras comunidades, sendo este número constantemente alterado (e crescente) no cenário nacional. Os signos e discursos que se interligam à identidade cumprem uma função de afirmação e resistência, que Bhabha (1998, p. 84) descreve da seguinte forma:

Cada vez que o encontro com a identidade ocorre no ponto em que algo extrapola o enquadramento da imagem, ele escapa à vista, esvazia o eu como o lugar da identidade e da autonomia e - o que é mais importante - deixa um rastro resistente, uma mancha do sujeito, um signo de resistência. Já não estamos diante de um problema ontológico do ser, mas de uma estratégia discursiva do momento da interrogação, um momento em que a demanda pela identificação torna-se, primariamente, uma reação a outras questões de significação e desejo, cultura e política.

\section{Tradição}

A tradição exerce uma função que devemos compreender minimamente, uma vez que embasa a 
afirmação de uma identidade e cultura próprias, que passam a ser assimiladas nos processos educativos produzidos por estes grupos, além de serem fatores de legitimação daquilo que seria uma cultura quilombola. Cumprindo uma função essencialmente política, a tradição passa a ser assimilada pelos grupos etnicamente diferenciados como um instrumento de valorização e legitimidade, tendo na manutenção/transmissão de uma cultura específica os aportes que os legitimariam como sujeitos de direito.

Utilizando uma conceituação antropológica daquilo que poderia ser entendido por tradição, Antônio Carlos de Sousa Lima (2012) entende que as tradições seriam resultantes da ação coletiva dos grupos sociais, tendo autenticidade pela assimilação dos seus sujeitos, não devendo ser, portanto, tida como autêntica mediante sua perpetuação no tempo, mas sim por sua vitalidade social. Em relação aos remanescentes de quilombos, o apelo a uma tradição comum extrapola as especificidades de cada comunidade, havendo uma concepção entre elas de uma trajetória comum e coletiva, que tem sua legitimidade na resistência à escravização e no processo de aquilombamento. Para além de uma concepção de origem comum entre esses grupos, o uso da cultura - representada principalmente em suas manifestações culturais, religiosidade, danças e fabricação de objetos - torna-se uma estratégia, considerando que:

Muitas tradições aparecem como sinais diacríticos nas etnicidades e são construções culturais que funcionam significando e delimitando, no discurso nativo, uma cultura própria. Em tais processos, a referência ao passado é importante para tornar legítimo o caráter tradicional, pois este, apoiado numa retórica de transcendência temporal, acaba por afirmar a historicidade da cultura. São pessoas reconhecidas como porta-vozes que devem deter a legitimidade para estabelecer as bases tradicionais sobre as quais a existência dos próprios grupos se funda. (LIMA, 2012, p. 194).

Mais do que um instrumento de manutenção cultural e de legitimidade política, a tradição está presente nas formas de se educar nessas comunidades, estando diretamente ligada à formação ampla do sujeito quilombola, sendo um dos elementos que contribuem para sua assimilação ao grupo e para um sentimento de pertencimento, tendo nela o ponto ao qual cada sujeito se interliga à sua memória e identidade.

\section{Narrativas}

A transmissão dos saberes e práticas relacionadas à cultura de cada grupo social é uma forma de perpetuá-lo no futuro, através de sua experiência acumulada numa memória que se mantenha organizada no tempo histórico. Para Raul Iturra (1994, p. 2), o processo educativo é, em síntese, a transmissão de saberes e fazeres de determinados grupos, "adquiridos em sua experiência histórica, às gerações mais jovens, tendo a transmissão oral um importante papel neste processo, a fim de inserir os mais novos nas taxonomias culturais".

A referência no passado se faz presente nas inúmeras narrativas que pudemos observar em campo, entre jovens e lideranças mais velhas, estando toda uma legitimidade enquanto grupo étnico numa herança cultural, o que pode ser sintetizado no conceito de tradição. A ideia de serem guardiões de uma tradição que se associa à uma história de resistência e de luta pela sobrevivência reforça a necessidade de reproduzir tais aspectos e de transmiti-los às novas gerações, a fim de resguardar tais saberes. $\mathrm{O}$ papel do narrador - geralmente uma pessoa de referência, quer um dos mais velhos, quer um mestre ou uma liderança (religiosa e/ou política) - pode ser entendido como um dos pilares de sustentação das tradições de origem africana e afro-brasileira entre as comunidades remanescentes de quilombos, que mantêm viva parte desses aspectos. Na comunidade de Carrapatos da Tabatinga percebe-se o papel importante desempenhando pela memória do cativeiro, a religiosidade - no caso, a umbanda - e as manifestações culturais como principais dimensões a afirmar sua afro-descendência.

\section{Memória}

Para analisar o uso da memória entre grupos, sobretudo no caso quilombola, faz-se imprescindível compreendermos que ela não é apropriada de forma natural, inconsciente e destituída de qualquer intencionalidade. Ao contrário, o recurso a uma memória, sobretudo a uma memória coletiva, por 
um determinado grupo acaba por cumprir uma função social da memória e da identidade, mediante a relação transmitir-receber. Tal relação é relevante em nossa pesquisa, uma vez que sintetiza parte significativa das formas de se educar os sujeitos quilombolas no interior da comunidade. Retomando Candau (2011), a transmissão das memórias é parte integrante dos processos de socialização e de educação de determinado grupo, o que pode auxiliar-nos na identificação deste processo na comunidade de Carrapatos da Tabatinga. Apesar de parte significativa dos membros da comunidade não ter vivido e nem mesmo conhecido seu território originário, a lembrança acerca de seu processo migratório é bastante viva nas narrativas. Tal aspecto, pode ser entendido sob a perspectiva de que:

Em um mesmo grupo, essa transmissão repetida várias vezes em direção a um grande número de indivíduos estará no princípio da reprodução de uma dada sociedade. No entanto, essa transmissão jamais será pura ou uma 'autêntica' transfusão memorial, ela 'não é assimilada como um legado de significados nem como a conservação de uma herança', pois, para ser útil às estratégias identitárias, ela deve atuar no complexo jogo da reprodução e da invenção, da restituição e da reconstrução, da fidelidade e da traição, da lembrança e do esquecimento. (CANDAU, 2011, p. 106, grifo do autor).

A memória coletiva teria sentido mediante consciências individuais dos membros de determinado grupo, estando a sobrevivência de determinada história/fato interligada à manutenção de sua memória, podendo a mesma ser alterada de geração para geração. As relações de tempo podem ser entendidas como subjetivas, uma vez que a cronologia histórica nem sempre é "fiel" à realidade do fato em si. O que nos auxilia neste processo é a identificação dos marcos relativamente imutáveis, que estão presentes na narrativa de sujeitos distintos acerca de um determinado fato. Para Halbwachs (1968), a memória coletiva está diretamente relacionada àquilo que ele designa como comunidade afetiva, uma vez que há uma interação entre indivíduos do mesmo grupo, que acabam por "negociar" os acontecimentos que serão enfatizados.

O interessante em observarmos tais aspectos sobretudo para as análises propostas no presente trabalho - se dá ao fato de todos serem perceptíveis tanto nas trocas cotidianas comunitárias, quanto nas mobilizações promovidas pelos coletivos sociais quilombolas. Nesse ponto, é possível afirmarmos que existe uma relação proximal - e por que não, indissociável - entre as experiências e concepções presentes tanto nas comunidades quanto nos movimentos sociais. Em outras palavras, o movimento assume as reivindicações e expectativas oriundas das individualidades de cada contexto quilombola, sendo este um reflexo das questões que já se fazem presentes do micro para o macro.

\section{Considerações finais}

As percepções trazidas acerca dos valores e das formas de transmissão que compõem o que consideramos parte das formas de se educar entre os remanescentes de quilombos, manifestas tanto no caso da comunidade pesquisada quanto no movimento quilombola representado pela N'Golo, foram o objeto de análise do presente trabalho. Transitando entre os espaços da comunidade e das mobilizações, diversos aspectos comuns puderam ser identificados ao longo de nossas interações com os sujeitos que atuam em ambos os espaços. A fim de verificar a continuidade e a projeção que estes sujeitos levam de suas experiências individuais para as experiências coletivas, é possível afirmar que existe uma projeção de causa, tornando-a comum, inerente a todos os sujeitos, independente do espaço sociogeográfico em que se inserem.

Ao considerarmos os discursos e observações apreendidos das lideranças quilombolas mais atuantes, a noção coletiva de uma causa comum é sintetizada em expressões como "nossa nação" e "nossos irmãos", tidas como uma concepção ideológica coletiva. Nesse processo, a memória é a principal responsável por conectar as individualidades de cada sujeito a uma identificação coletiva, o que é descrito por Michel Pollack (1992, p. 201) como acontecimentos vividos por tabela, ao qual: “[...] a memória deve ser entendida também, ou sobretudo, como um fenômeno construído coletivamente e submetido a flutuações, transformações, mudanças constantes."

A partir desse trecho, é possível afirmarmos que a luta quilombola constitui-se e ganha relevância, do ponto de vista legal, numa percepção coletiva, 
na qual o reconhecimento pressupõe uma coletividade. Tal fenômeno também se manifesta ao reverso, já que o processo de (des)invisibilização das comunidades quilombolas se constituíra mediante reconhecimento legal destes grupos enquanto populações tradicionais etnicamente diferenciadas. A ressemantização do termo quilombo e o reconhecimento de uma categoria social dos remanescentes de quilombos é o ponto de partida das mobilizações de milhares de comunidades localizadas em diversos estados do Brasil, em prol de um direito coletivo.

Sob a perspectiva de uma cultura diferenciada, a qual a antropóloga Manuela Carneiro da Cunha (2009, p. 312, grifo do autor) conceitua de "cultura com aspas", esses grupos passam a se reconhecer e a se organizar em torno de um ponto comum, traduzido pela autora como uma corrida em busca da afirmação:

Do mesmo modo, a 'cultura', uma vez introduzida no mundo todo, assumi um novo papel como argumento político e serviu de 'arma dos fracos', o que ficará particularmente claro nos debates em torno dos direitos intelectuais sobre os conhecimentos dos povos tradicionais.

Nesse processo de reconhecimento, a adoção e a visibilidade de suas formas e estratégias educativo-formativas são de suma relevância para compreendermos a relação entre educação e movimentos sociais. À luz dessa autora, essa relação se dá a partir do momento em que estes grupos passam a reconhecer seu valores étnico-culturais, trazendo para o debate político suas formas próprias de reprodução sociocultural e, consequentemente, de se educarem. Este ponto é de suma relevância na proposição de uma modalidade de Educação Quilombola, uma vez que reconhece seus repertórios, performances, cosmovisão, interação com o meio, sobretudo na relação com o território tradicional e na compreensão de sua identidade, que os tornam quilombolas.

Por fim, vale aqui ressaltar o caráter formativo indispensável que os movimentos e coletivos sociais assumem no âmbito das disputas políticas, sobretudo no campo educativo, sendo o principal instrumento de difusão e defesa das questões que demandam maior intervenção por parte dos órgãos públicos. Mais do que isso, o movimento é responsável pela constituição de um pensamento simbólico-ideológico de grupo, formando sujeitos engajados e apropriados de uma identidade que supera as fronteiras geográficas entre as comunidades. Endossadas por um discurso próprio de classe, as propostas e reinvindicações dos grupos quilombolas nada mais são do que uma resposta frente ao histórico de exclusões e desigualdades enfrentadas, que Miguel Arroyo (2012, p. 39) endossa:

Essas tensões são respostas, repolitizadas na atualidade pela diversidade de coletivos sociais, étnicos, raciais, de gênero e orientação sexual dos campos e periferias em suas ações e movimentos que incorporam pedagogias e saberes acumulados por outras ações e movimentos de educação, emancipação. Mas vão além. Os campos de suas lutas os obrigam a inventar processos e pedagogias com outras radicalidades e virtualidades formadoras e emancipadoras.

Inversamente, essas pedagogias são desenvolvidas no interior de cada comunidade e reproduzidas entre seus sujeitos, o que nos aponta a necessidade de reconhecer e legitimar outras formas de se educar, sobretudo aquelas que antecedem a inserção de seus sujeitos no espaço escolar. Reconhecer estes saberes e práticas pedagógicas endossam a luta quilombola e o reconhecimento de seus aspectos tradicionais, uma vez que a Educação se torna importante instrumento de luta e de promoção social de seus sujeitos

Conscientes de si, do que reivindicam e da identidade que representam, interagir com essas comunidades nos aponta para novas perspectivas teóricas no campo da educação, sobretudo se considerarmos o recorte da Educação Quilombola. Portanto, faz-se necessário o reconhecimento e a valorização destes sujeitos, a fim de que, conjuntamente, a proposta educacional que os tenha por público-alvo interaja com eles de forma horizontal, dando voz a estes grupos. Ancorados numa organização simbólica de matriz africana, seus modos de educar devem contemplar tais valores, a fim de manter vivas suas tradições para a posteridade e de garantir a perpetuação de sua memória coletiva, que se configura em parte significativa de nossa história. 


\section{REFERÊNCIAS}

A FILHA de São Sebastião. Produção: Caturra Digital Filmes. Belo Horizonte, 2014. Disponível em: <https://www. youtube.com/watch?v=6nHORCY-EEE $>$. Acesso em: 08 ago. 2017.

ALVES-MAZZOTTI, Alda Judith; GEWANDSZNAJDER, Fernando. O método nas ciências naturais e sociais: pesquisa quantitativa e qualitativa. 2. ed. São Paulo: Pioneira, 2004.

ANGROSINO, Michael. Etnografia e observação participante. Tradução José Fonseca. Porto Alegre: Artmed, 2009.

ARROYO, Miguel G. Outros sujeitos, outras pedagogias. Petrópolis, RJ: Vozes, 2012.

BAKHTIN, M. M. Marxismo e filosofia da linguagem: problemas fundamentais do método sociológico da linguagem. 13. ed. São Paulo: Hucitec, 2009.

BHABHA, Homi K. O local da cultura. Belo Horizonte: Editora UFMG, 1998.

BRANDÃO, Carlos Rodrigues; ASSUMPÇÃO, Raiane. Cultura rebelde: escritos sobre a educação popular ontem e agora. São Paulo: Editora Instituto Paulo Freire, 2009.

BRASIL. Presidência da República. Casa Civil. Decreto no 4.887, de 20 de novembro de 2003. Regulamenta o procedimento para identificação, reconhecimento, delimitação, demarcação e titulação das terras ocupadas por remanescentes das comunidades dos quilombos de que trata o art. 68 do Ato das Disposições Constitucionais Transitórias. Brasília, DF, 2003a. Disponível em: <http://www.planalto.gov.br/ccivil_03/decreto/2003/d4887.htm>. Acesso em: 08 ago. 2017.

Presidência da República. Casa Civil. Lei no 10.639, de 09 de janeiro de 2003. Altera a Lei no 9.394, de

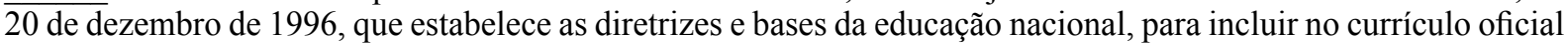
da Rede de Ensino a obrigatoriedade da temática "História e Cultura Afro-Brasileira", e dá outras providências. Brasília, DF, 2003b. Disponível em: <http://www.planalto.gov.br/ccivil_03/leis/2003/L10.639.htm>. Acesso em: 08 ago. 2017.

Ministério da Educação. Diretrizes Curriculares Nacionais para a Educação das Relações Étnico-Raciais e para o Ensino de História e Cultura Afro-Brasileira e Africana. Brasília, DF, 2012.

CANDAU. Joel. Memória e identidade. Tradução de Maria Letícia Ferreira. São Paulo: Contexto, 2011.

CENTRO DE DOCUMENTAÇÃO ELOY FERREIRA DA SILVA (CEDEFES). Comunidades quilombolas de Minas Gerais: entre direitos e conflitos. Belo Horizonte, 2013.

Por uma educação básica do campo: cadernos de textos do $1^{\circ}$ Encontro Estadual de Minas Gerais. Belo Horizonte, 1998.

CUNHA, Manuela Carneiro da. "Cultura" e cultura: conhecimentos tradicionais e direitos intelectuais. In:

(Org.). Cultura com aspas e outros ensaios. São Paulo: Cosac Naify, 2009. p. 311-373.

DANDARAS: a força da mulher quilombola. Direção e Ana Carolina e Amaralina Fernandes. Produção Independente. Brasília, DF, 2015. Disponível em: <https://www.youtube.com/watch?v=RSW3uEfk4QU>. Acesso em: 08 ago. 2017.

FLICK, Uwe. Introdução à pesquisa qualitativa. Tradução Joice Elias Costa. 3. ed. Porto Alegre: Artmed, 2009.

FREIRE, Paulo. Educação como prática da liberdade. 15. ed. Rio de Janeiro: Paz e Terra, 2013.

HALBWACHS, Maurice. A memória coletiva. 2. ed. Paris: Presses Universitaires de France, 1968.

HALL, Stuart. Da diáspora: identidades e mediações culturais. Belo Horizonte: Editora UFMG, 2009.

ITURRA, Raúl. O processo educativo: ensino ou aprendizagem? Revista Educação, Sociedade \& Culturas, Porto, Portugal, n. 1, 1994. Disponível em: <http://www.fpce.up.pt/ciie/revistaesc/ESC1/Iturra.pdf $>$. Acesso em: 08 ago. 2017.

LARROSA, Jorge. Tecnologias do eu e educação. In: SILVA, Tomaz Tadeu. O sujeito da educação. Petrópolis, RJ: Vozes, 1994. p. 35-86.

LIMA, Antônio Carlos de Souza. Antropologia e direito: temas antropológicos para estudos jurídicos. Brasília, 
DF: Associação Brasileira de Antropologia/Nova Letra, 2012.

PINTO, Regina Pahim. Movimento negro e educação do negro: ênfase na identidade. Cadernos de Pesquisa, São Paulo, n. 86, p. 25-38, ago. 1993.

POLLACK, Michael. Memória e identidade social. Estudos Históricos, Rio de Janeiro, v. 5, n. 10, p. 200-212, 1992. RIBEIRO, Elisa Antônia. A perspectiva da entrevista na investigação qualitativa. Evidência: olhares e pesquisa em saberes educacionais, Araxá, MG, n. 4, p. 129-148, maio 2008.

ROSÁRIO, Lourenço Joaquim da Costa. A narrativa africana de expressão oral. Luanda, Angola: Angolê, 1989. SCOTT, Joan W. A invisibilidade da experiência. Revista Projeto História, São Paulo, n. 16, p. 297-325, fev. 1998. SILVA, Tomaz Tadeu da (Org.). Identidade e diferença: a perspectiva dos estudos culturais. 15. ed. Petrópolis, RJ: Vozes, 2014.

VENDRAMINI, Celia Regina; MACHADO, Ilma Ferreira (Org.). Escola e movimento social: experiências em curso no campo brasileiro. São Paulo: Expressão Popular, 2011.

Recebido em: 01/05/2017

Aprovado em: 26/06/2017 